\title{
Factors related to the use of community nursing services in The Netherlands
}

\author{
Ada Kerkstra PhD \\ Co-ordinator of Community Nursing Research \\ and Trees Vorst-Thijssen RN \\ Research Fellow, Netherlands Institute of Primary Health Care, Utrecht, The Netherlands
}

KERKSTRA A \& VORST-THIJSSEN T (1991) Journal of Advanced Nursing 16, 47-54

Factors related to the use of community nursing services in The Netherlands

This study aims to identify factors important in explaining the nature of community nursing care received by patients in their homes because little is known about the relation between individual characteristics of patients receiving nursing care and the nature of care delivered by community nurses During a period of 2 weeks a representative sample of 137 community nurses and 49 community nurses' auxiliaries at 47 different locations paid a total number of 12847 home visits to provide care to 3315 patients For each home visit, patient's characteristics, the nature of care delivered by the nurse and the length of the home visit was recorded The results suggested that three groups of patients could be identified in terms of the nature of nursing care received at home First, patients who were older, who were also receiving informal care and did not suffer from psychosocial problems, were most likely to receive assistance in their activities of daily living Second, patients suffering from multiple disorders, whose situation was assessed as unstable, and those who did not suffer from psychosocial problems were most likely to receive technical nursing care These patients were visited most often Finally, male patients suffering from multiple disorders, whose situation was assessed as unstable, especially when new mental or social problems emerged, were most likely to receive psychosocial support and education from the community nurse These visits appeared to be the most time-consuming

\section{INTRODUCTION}

The community nursing services in The Netherlands have become all the more important, given the policy of keeping the people at home in the community for as long as possible, and the reduction in the number of beds in hospital in addition to this, as is the case in other countries (Baker et al 1987, Evashwick et al 1984, Speakman 1984), there is an Correspondence Dr Ada Kerkstra NIVEL (Netherlands Institute of Prmary Health Care), PO Box 1568, 3500 BN Utrecht, The Netherlands increasing proportion of the population in the $65+$ age group While in 1960 only $87 \%$ of the Dutch population was aged 65 or older, in 1989 approximately $127 \%$ of the population fell into this category Current projections indicate that by the year 2000 approximately $14 \%$ will be classified as 'elderly' (Centraal Bureau voor de Statistiek 1990)

In addition to the fact that elderly people, in particular, make use of community nursing services (Nationale 
Krusvereniging 1986b), little is known about other charactenstics (e $g$ diagnosis, living situation) of the recipients of community nursing care and the nature of services being provided It also would be very useful for planning purposes to have information about the individual characteristics of patients which relate to the nature of the community nursing care they receive

A lot of research on the utilization of health services by older people has used the behavioural model of health service utilization developed by Andersen \& Newman (1973) In this behavioural model, the use of health services is defined as a function of illness level and the predisposing and enabling charactenstics of the individual (Andersen \& Newman 1973, Branch et al 1981, Evashwick et al 1984) Illness level comprises both subjective perceptions and objective judgement Predisposing factors are individual charactenstics that may affect need recognition or service utilization These characteristics may be classified as either demographic (age, sex, mantal status), social-structural (education, occupation) or health beliefs (Wolinsky et al 1983) Enabling characteristics are factors such as financial capacity to pay for care, insurance coverage, ability to get to the places where service is offered, and knowledge about the service network in the community (Wan \& Odell 1981)

This model has been used to study the influence of the illness level and predisposing and enabling factors on the utilization of hospitals, physicians, dental care and home care services (Branch et al 1981, Coulton \& Frost 1982, Evashwick et al 1984, Wolinsky et al 1983, Wan \& Odell 1981) Home care services, in the above-mentioned studies, included a combination of skilled nursing, home helps and meals services The dependent variable is generally dichotomous, $1 \mathrm{e}$ using or not using home care services during a penod in the past The independent factors are not related to the frequency or nature of care recerved The above-mentioned studies showed that illness level is the most important individual determinant of the use of home care services

\section{THE STUDY}

The present study aims to identify factors important in explaining the nature of community nursing care recelved by patients in their homes Patients receiving nursing care at home might differ among themselves with respect to age, sex, living situation, diagnosis, psychosocial problems, etc Furthermore, community nurses deliver different sorts of care to patients at home, e $\mathrm{g}$ technical nursing care, personal hygienic care, health education, and support with psychosocial problems (Dunnell \& Dobbs 1982, Nationale Kruisvereniging 1986a) The frequency and the length of home visits can also be variable (Speakman 1984) However, hittle is known about the relation between individual charactenstics of patients receiving nursing care at home and the nature of care delivered by community nurses

Unlike the above-mentioned research, using the behavcoural model of Andersen \& Newman to explan the use of home care services, the present study concerns only those patients receiving nursing care at home, whereas the other studies included both people using home care services as well as people not using such services

More specifically, this study has attempted to find answers to the following questions

1 What are the individual characteristics of patients cared for by community nurses at home?

2 What kind of nursing care do these patients receive at home?

3 Which individual characteristics of the patients affect the nature of care received?

\section{METHOD}

A representative sample of 137 community nurses and 49 community nurses' auxilianes at 47 different locations in The Netherlands were studied Dunng a penod of 2 weeks, they recorded all their activities and the tasks undertaken, e g home visits, sessions held at a child health clinic, consultation with other primary care providers and travelling They also kept records of the time spent on these activities All the auxilianes and 108 community nurses worked during office hours, and 29 community nurses worked only durng the weekends, in the evening or at night They recorded their activities on diary sheets which had been developed and tested for reliability and validity in a pilot study (Kerkstra \& de Wit 1988)

The study is restricted to the self-recording of patient care contact at home In the 2-week penod, the nurses paid a total number of 12847 home visits to provide care to 3315 patients For each home visit, the patient's name, sex, age, living situation (i e whether alone, or with spouse, family, etc ), diagnosis, the motives for visiting the patient at home and whether or not the patient was recerving informal care, were recorded They also recorded the time of arrival and departure and their activities durnng the home visit The main categones of care distinguished were-

1 hygienic care bathing the patient, help with washing and dressing, care for hair, nails and feet, and help with the lavatory, 
Table 1 Factor analysis of care delivered to the patients $(n=3315)$ by the community nurses

\begin{tabular}{|c|c|c|c|}
\hline \multirow[b]{2}{*}{ Type of care } & \multicolumn{3}{|c|}{ Factor loadings } \\
\hline & Factor 1 & Factor 2 & Factor 3 \\
\hline Health education & 075 & -004 & 009 \\
\hline Support in following therapy & $0 \cdot 71$ & -001 & 003 \\
\hline Support in psychosocial problems & 066 & -010 & -019 \\
\hline Support for informal caregivers & $\mathbf{0} 5 \mathbf{0}$ & 027 & 011 \\
\hline Personal hygienic care & -008 & 084 & 004 \\
\hline Household activities & 007 & $\mathbf{0 . 8 1}$ & -002 \\
\hline Technical nursing care & -025 & 013 & 077 \\
\hline Administration & 029 & -005 & 0.65 \\
\hline Percentage of variance & 240 & 190 & 127 \\
\hline
\end{tabular}

2 household activities preparing food and drinks, cleaning the bathroom, etc,

3 technical nursing care care of pressure sores and wounds, stomacare, administration of medicines and catheterization,

4 health education giving information to the patient regarding the nature of the ilness, the use of medicines, the possibility of self-care and informal care, auxiliary apparatus and adaptation of the house,

5 support in carrying out therapy to help and to encourage the patient with rehabilitation exercises, to support the patient when he has to follow a stnct diet,

6 support in psychosocial problems listening, empathic understanding, advising,

7 support for informal caregivers advice to relatives, giving instructions on nursing care, discussing the workload of the informal caregivers,

8 administration recording information about the patients, and the care given to the patient on the patient's record card

The examples given above for each category provide an indication of the kinds of activities included in a category, but are not exhaustive Finally, the nurses recorded the degree of instability in the patient's situation, ie they recorded whether new physical symptoms, mental or social problems were detected

\section{Dependent and independent variables}

To answer the third research question, Andersen \& Newman's (1973) model of health services utilization was adapted for use in our study and the independent variables were grouped into illness level and predisposing factors In our model, illness level included the number of different diagnoses of the patient's condition, the degree of instability in patient's situation, and whether there was a psychological or social reason for the home visit Predisposing variables included age, sex, living situation and whether the patient was receiving informal care (social network) Enabling factors have been excluded from our study because the patients all received nursing care at home Furthermore, since 1980 , the services of community nurses have been financed by a system of public insurance based on the General Act on Exceptional Medical Costs (AWBZ) This means that, in principle, everybody in The Netherlands is entitled to receive care from communuty nurses, where such care is needed The services of community nurses are also directly accessible to the public, $1 \mathrm{e}$ people do not have to be referred by a physician to use the service

The dependent variable in our model was the nature of nursing care received by the patient In order to define the indicators of the dependent variable, a principal components analysis was done with orthogonal varimax rotation From this analysis, three factors could be identifed, explaining $557 \%$ of the vanance (Table 1) A category of care was considered to be highly loaded on a factor, If it was equal to or greater than 050 on the given factor and less than 030 on any other factor

The first factor could be labelled 'support and education' Factor 2 contained categones in respect of assistance with the activities of dally living (ADL) of the patients, and the third factor that emerged could be labelled 'technical nursing care' These three factors served as indicators of the nature of nursing care received Accordingly, each patient was assigned a score on each of these types of nursing care 
Table 2 Percentage distribution of patients receiving nursing care at home by age, sex, living situation and informal care

\begin{tabular}{lcc}
\hline & $\begin{array}{l}\text { Males } \\
(n=1171)\end{array}$ & $\begin{array}{l}\text { Females } \\
(n=2144)\end{array}$ \\
\hline Age & & \\
$0-10$ & 13 & 05 \\
$11-20$ & 08 & 0.3 \\
$21-30$ & 08 & 13 \\
$31-40$ & 14 & 29 \\
$41-50$ & 26 & 34 \\
$51-60$ & 76 & 66 \\
$61-70$ & 150 & 16.2 \\
$71-80$ & 336 & 321 \\
$80+$ & 370 & 367 \\
& & \\
Living situation & & \\
Living alone & 240 & 458 \\
Living together with spouse & 603 & 330 \\
Living with other people & 157 & 212 \\
& & \\
Receiving informal care & & \\
Yes & 843 & 76.2 \\
No & 157 & 238 \\
& & \\
\hline
\end{tabular}

\section{RESULTS}

\section{Individual characteristics of patients receiving} nursing care at home

\section{Predisposing vanables}

The patients receiving community nursing care were predominantly women (647\%), and $865 \%$ of the patients were at least 60 years old, and approxımately $72 \%$ were over 70 years of age (Table 2) The average age of all patients was 736 years There were no differences in age between males and females

Conversely, living situation and receiving informal care were related to age The mean age of patients living alone (77 7 years) was significantly higher $(t=-1358, P=$ $0000)$ than the mean age of patients living together with spouse or with other people ( 71 years) The mean age of patients receiving informal care (749 years) was signifcantly higher $(t=-847, P=0.000)$ than the mean age of patients not receiving informal care (68 5 years) This unexpected finding was caused by the presence of a relatively young group of 326 patients with a mean age of 61 years, who were living together with spouse or other people, but did not receive informal care However, further analysis showed that there was no interachion between living alone
Table 3 Diagnoses of patients receiving nursing care at home $(n=3315)$

\section{Dragnosis}

Percentage

\begin{tabular}{lr} 
Musculoskeletal disorders & 271 \\
Cardiovascular diseases & 172 \\
Diabetes & 149 \\
No diagnosis (frailty, old age) & 135 \\
Cancer & 126 \\
Neurological disorders & 122 \\
Cerebral haemorrhage & 96 \\
Dementia Senilis & 66 \\
Chronic obstructive pulmonary diseases & 61 \\
Other diagnosis & 186 \\
\hline
\end{tabular}

and receiving informal care with age as dependent vanable ( $F=131, P=0$ 20)

Furthermore, patients living alone were receiving less informal care compared with patients living together with spouse or other people ( $\mathrm{ph}=016, P=0000$ ) This is consistent with the finding that informal care was predominantly received from the spouse $(34 \%)$ or from other people living with the patient (19\%) In addition to this, living situation and receiving informal care were related to the sex of the patient more female patients were living alone ( $\mathrm{ph}=022, P=0.000)$ and male patients more often received informal care $(\mathrm{ph} 1=0.12, P=0.000)$

Illness level

Table 3 shows the diagnoses of the patients The most common diagnosis was musculoskeletal disorders (including arthritis), followed by cardiovascular diseases, diabetes and cancer The figures indicate that a substantial number of patients were suffenng from chronic problems limiting their mobility In nearly $14 \%$ of the patients, no diagnosis was made They received nursing care because of their age and frailty More than half of the patients (59\%) had one diagnosis, $22 \%$ of the patients had two diagnoses and $6 \%$ had three or more diagnoses

The most common motive for the home visits was to give care related to the diagnosis, followed by personal care activities such as bathing the patient About $6 \%$ of the patients received aftercare Aftercare has been defined as nursing care received at home within a period of 4 weeks after discharge from hospital (Verschuren 1985) Around $10 \%$ of the patients were visited for reasons of reassurance, i.e the community nurse checked to see that nothing was amiss with the patient This was predominantly in the case 
Table 4 Motives for visiting the patient at home $(n=3315)$

Motives*

Percentage

Terminal care

Aftercare

32

Patient education

57

Reassurance

48

Support in psychosocial problems

103

68

676

275

Personal care actıvities

Other motives
Table 5 Categones of care delivered to the patients $(n=3315)$ by the community nurses

Categones of care

Percentage

Personal hygienic care $\quad 584$

Technical nursing care $\quad 598$

Household activities $\quad 228$

Health education $\quad 387$

Support in realızing therapy $\quad 277$

Support in psychosocial problems $\quad 375$

Support for informal caregivers $\quad 302$

Adminustration $\quad 693$

Table 6 Correlations between types of nursing care (factors) and frequency and duration of the home visits $(n=3315)$

psychosocial reasons Finally, 3\% of the patients were visited in order to give them terminal care About half of the patients receiving termınal care were suffering from cancer

The situations of most patients $(702 \%)$ were recorded as stable, that is the community nurses did not observe new physical symptoms, mental or social problems In $172 \%$ of the patients, deterioration emerged in only one of the three areas (physical, mental or social), whereas $58 \%$ of the patients showed new symptoms in two areas In addition, in $6.8 \%$ of the patients a detenoration was observed in physical, mental, as well as social respects

\section{Nature of community nursing care received by patients}

The average number of home visits per patient during the 2 weeks was four with a range of one to 58 visits The average length of visits was 32 minutes with a range of 2 minutes to $I$ hour and 35 minutes The number of home visits was negatively related to the length of the visits $(r=-0.15, P=0.000$ ) Patients suffering from diabetes were visited most frequently however, these visits were the least time-consuming

More than half of the patients received personal hygienic care such as bathing, grooming and dressing, or technical nursing care like care of pressure sores and wounds, stoma care and administration of medicnes (Table 5) Health education was given to nearly $40 \%$ of the patients This mostly concerned information on the nature of illness, the use of medicines, and self-care options In addition, $28 \%$ of the patients were encouraged to do rehabilitation exercises, to
Number of Length of

home visits home visits

\begin{tabular}{|c|c|c|}
\hline & $\begin{array}{l}\text { Number of } \\
\text { home visits }\end{array}$ & $\begin{array}{l}\text { Length of } \\
\text { home visits }\end{array}$ \\
\hline Supporting and education & $-011^{*}$ & $036^{*}$ \\
\hline Assistance in $\mathrm{ADL}$ & $007^{*}$ & $011^{*}$ \\
\hline Technical nursing care & $018^{*}$ & $-010^{*}$ \\
\hline
\end{tabular}

$-P<0-001$

$\mathrm{ADL}=$ activithes of dally living

follow a diet as prescribed, or to use auxiliary equipment Nearly $40 \%$ of the patients were given support for psychosocial problems Acceptance of illness or physical disability, feelings of loneliness and problems concerning admission to the hospital or nursing home were the most common psychosocial problems among the patients Finally, informal caregivers received support from the community nurse in $30 \%$ of the cases As mentioned before, from a principal components analysis carned out on these categones of nursing care, three factors could be identified (a) support and education, (b) assistance in ADL, and (c) technical nursing care Table 6 shows that giving support to the patient or to the informal caregivers together with patient education was positively related to the length of the home visit and slightly negatively related to the frequency of home visits

Conversely, delivering technical nursing care was posihvely related to the number of home visits and sightly negatively related to the duration of the home visits Assistance given by the community nurse in the activities of daly living of the patients was moderate in relation to the frequency and duration of the home visits These findings suggest that supporting patients in, for instance, psychosocial problems or giving health education were the most 
Table 7 Regression of nature of care received by the patients $(n=3315)$ on illness level and predisposing vanables

\begin{tabular}{|c|c|c|c|}
\hline & $\begin{array}{l}\text { Supporting and } \\
\text { education }\end{array}$ & $\begin{array}{l}\text { Assistance } \\
\text { in ADL }\end{array}$ & $\begin{array}{l}\text { Technical } \\
\text { nursing care }\end{array}$ \\
\hline Independent variables & $\beta$ & $\beta$ & $\beta$ \\
\hline \multicolumn{4}{|l|}{ Illness level } \\
\hline Number of diagnoses & $0.11^{*}$ & 0.05 & $018^{*}$ \\
\hline Degree of instability & $031^{*}$ & 0.04 & $010^{*}$ \\
\hline $\begin{array}{l}\text { Psychological or social } \\
\text { reasons for home visits }\end{array}$ & $027^{*}$ & $-033^{*}$ & $-019^{*}$ \\
\hline \multicolumn{4}{|l|}{ Predısposing charactenstics } \\
\hline Age & -0.04 & $0.15^{*}$ & 0.04 \\
\hline $\operatorname{Sex}(1=$ male, $2=$ female $)$ & $-011^{*}$ & -0.02 & 0.04 \\
\hline $\begin{array}{l}\text { Living alone ( } 1=\text { living } \\
\text { together, } 2=\text { living alone) }\end{array}$ & -0.06 & 0.00 & -001 \\
\hline $\begin{array}{l}\text { Recelving informal care } \\
(1=\text { no, } 2=\text { yes })\end{array}$ & 0.06 & $018^{*}$ & 005 \\
\hline $\mathrm{R}^{2}(\mathrm{I})$ & 0.18 & 0.11 & 0.09 \\
\hline $\mathbf{R}^{2}(\mathrm{I}+\mathrm{P})$ & 0.20 & 0.17 & 0.09 \\
\hline
\end{tabular}

${ }^{*} P<0.0001$

time-consuming nursing care activities, whereas patients receiving technical care were visited most frequently

\section{Individual characteristics of patients related to the} nature of care received

In the present study, nature of care received had been measured by three indicators (a) support and education, (b) assistance in $\mathrm{ADL}$, and (c) technical nursing care The independent vanables were grouped into two blocks illness level and predisposing characteristics $A$ hierarchical regression analysis was performed with the blocks entered sequentrally This enabled examination of the effects of predisposing charactenstics after illness level had been taken into account Table 7 presents $R^{2}$ resulting from the addition of each block to the model Standardized coefficients for the final model, simultaneously including all the independent variables, are also presented

The vanable 'psychological or social reasons for home visits' included a combination of three motives for visiting the patient support in psychosocial problems, reassurance and patient education. The amount of vanance in the nature of care explained by the model adapted from Andersen \& Newman (1973) is rather low Only $9 \%$ of the vanance was explained in technical nursing care, $17 \%$ of the vanance in assistance in $A D L$, and $20 \%$ of the varnance in support and education. Predisposing characteristics and the absence of a psychological or social reason for visiting the patient had the greatest effect on the assistance in activities of daly living received by the patients Patients who were older, those who also were receiving informal care, and were not visited for psychological or social reasons were most likely to receive assistance in $\mathrm{ADL}$ from the community nurse

Illness level is the major reason for receiving technical nursing care from the community nurse Pahents suffening from multiple disorders, those who were not visited for psychological or social reasons, and patients whose situation was assessed as unstable were most likely to receive technical nursing care Also, illness level had the greatest effect on explaining whether or not patients received support or education from the community nurse Only one predisposing characteristic had a significant effect on receiving support and education when the influence of the other vanables in the model was controlled male patients were significantly more likely than female patients to receive support and education from the community nurse

\section{DISCUSSION}

This study has shown that patients receiving community nursing care were predominantly elderly ( $72 \%$ were over $70)$, females ( $64.7 \%$ ) and about $46 \%$ of these female patients were living alone In a study carned out in England, similar findings were reported (Dunnell \& Dobbs 1982) Most of the patients received informal care from spouse or from other people living with the patient. Female patients received informal care less often than male patients 
Developments in the elderly as a group will be charactenzed by an increase in the elderly aged over 80 years and an increase in females living alone Consequently, the possibilities of informal care will decrease and the use of professional home services will increase

A substantial number of patients were suffening from chronic problems limiting their mobility, and more than a fourth of them were suffenng from multiple disorders $A$ wide vanety of nursing care was received by the patients More than half of the patients received personal hygienic care or technical nursing care Besides these more 'traditional' sorts of nursing care, many patients were supported to their psychosocial problems, received health education or were encouraged in following prescribed therapies Informal caregivers also often received support from the community nurses

In the present study, the Andersen \& Newman (1973) model of utilization of health services was adapted to explain the nature of nursing care received by patients at home The predictor factors were illness level and the predisposing charactenstics of the patients However, the amount of variance in the nature of nursing care received explained by this model was rather low Only $9 \%$ of the variance was explained in technical nursing care, $17 \%$ of the variance in receiving assistance by $A D L$ and $20 \%$ of the variance in support and education The findings from these analyses of the Andersen \& Newman (1973) model suggest that the model, as used in this investigation, makes only a modest contribution to our understanding of the knd of care received by different patients from community nursing services In this respect, our findings are congruent with results of previous research into the utilization of home care services

Previous research showed that only 13 to $43 \%$ (Evashwick et al 1984, Coulton \& Frost 1982, Wolinsky et al 1983, Kivela et al 1986) of the vanance was explained by the use of home care services Furthermore, our analyses only partly used the Andersen \& Newman (1973) model Only a few predisposing vanables and indicators of illness level were used For example, measurements of the subjective need perceptions of the patients and functional status (ADL) were not included Other researchers (e g Bass Noelker 1987) have also emphasized the need to elaborate the Andersen \& Newman (1973) model further They suggested that concepts like social networks and informal caregivers needed more attention in the model

\section{Conclusion}

Our results suggested that three groups of patients could be identified in terms of the nature of the nursing care received at home First, those patients who were older, who were also receiving informal care and did not suffer from psychosocial problems, were most likely to receive assistance in their activities of daily living, e $g$ help with washing and dressing, prepanng food and drinks, from the community nurse Maybe the avallability of informal care providers is an essential condition for the option of caring for older patients with a low functional status at home These patients were visited with moderate frequency and the length of home visits also was moderate

Second, patients suffering from multiple disorders, whose situation was assessed as unstable, $1 \mathrm{e}$ where new physical symptoms emerged, and those who did not suffer from psychosocial problems were most likely to receive technical nursing care, e $\mathrm{g}$ care of pressure sores and wounds, administration of medicines and catheterization, from the community nurse These patients were visited most often

Finally, male patients suffering from multiple disorders, whose situation was assessed as unstable, especially when new mental or social problems emerged, were most likely to receive support and education from the community nurse Their informal care providers also received support and instructions These visits appeared to be the most timeconsuming, but were conducted less often than visits to patients who did need technical nursing care

\section{References}

Andersen R \& Newman J F (1973) Societal and individual determinants of medical care utilization in the United States Millbank Memorial Fund Quarterly 1, 95-124

Baker G , Bevan J M , McDonnell L \& Wall B (1987) Communty Nursing, Research and Recent Developments Croom Helm, London

Bass DM \& Noelker LS (1987) The influence of famuly caregivers on elder's use of in-home services an expanded conceptual framework. Jourmal of Health and Social Behaviour 28. 184-196

Branch L, Jette A, Evashwick C, Polansky M, Rowe G \& Diehr $P$ (1981) Toward understanding elders' health service utilization Journal of Communty Health 7(2), 80-92

Centraal Bureau voor de Statıstıek (1990) Statistisch Zakboek 1990 SDU Uitgevern, 's-Gravenhage

Coulton C \& Frost A.K (1982) Use of social and health services by the elderly Journal of Health and Social Behaviour 23, 330-339

Dunnell K \& Dobbs J (1982) Nurses Workng in the Community Her Majesty's Stationery Office, London

Evashwick C. Rowe G, Diehr P \& Branch L. (1984) Factors explaming the use of health care services by the elderly Health Seroices Research 19(3), 358-382 
Kerkstra A \& de Wit A.M J J (1988) Het werk van de wijkverpleging gemeten instrumentontwikkeling Verpleegkunde 3, 140-152

Kivela S, Pahkala K \& Tervo R (1986) Factors explaning the referral of elderly to home nursing or home help Health Policy 6, 73-85

Natıonale Krusvereniging (1986a) Een bilk op de wojkoerpleging Natıonale Kruisvereniging, Bunnik

Nationale Krusvereniging (1986b) Fetten en cuffers Nationale Kruisvereniging, Bunnik

Speakman I (1984) Measuring the immeasurable Nursing Times $80(22), 56-58$
Verschuren MID (1985) Selectrecntena Voor Nazorg Rujksuniversiteit Limburg, Vakgroep Verplegingswetenschap, Maastncht

Wan T TH \& Odell B G (1981) Factors of affectung the use of social and health services among the elderly Ageing and Society 1, 95-115

Wolınsky F D , Coe R.M , Miller, DK, Prendergast J M, Creel MJ \& Chavez MN (1983) Health services utilization among the noninstitutionalized elderly Joumal of Health and Social Behaotour 24, 325-337 
This document is a scanned copy of a printed document. No warranty is given about the accuracy of the copy. Users should refer to the original published version of the material. 